\title{
Zur Bestimmung der $\beta$-Glukuronidase im Serum
}

\author{
Von R. NiLIUS \\ Aus der I. Medizinischen Klinile der Universität Halle-Wittenberg \\ (Direktor: Prof. Dr. med. habil. K. H. Kroscb)
}

(Eingegangen am 29. Oktober 1965)

\begin{abstract}
Es wird eine Methode zur Bestimmung der $\beta$-Glukuronidase im menschlichen Serum beschrieben. Als Substrat diente biosynthetisch gewonnenes 8-Oxychinolin- $\beta$-D-glukuronid, und zur Anfärbung des fermentativ freigesetzten 8-Oxychinolin wurde Tetra-o-dianisidin benutzt. Nach Beschreibung der Methode und Erörterung der Enzymkinetik werden Vorzüge gegenüber anderen Aktivitätsmessungen der $\beta$-Glukuronidase im Serum diskutiert.
\end{abstract}

\begin{abstract}
A method is described for the determination of $\beta$-glucuronidase in human serum. The substrate is 8 -hydroxyquinoline- $\beta$-D-glucuronide, prepared biologically. Tetra-o-dianisidine is used as the colorimetric agent for the measurement of 8-hydroxyquinoline, which is released enzymically. Following a description of the method and the enzyme kinetics, the advantages over other methods for serum $\beta$-glucuronidase are discussed.
\end{abstract}

Gepaarte Glukuronsäuren sind im Pflanzen- und Tierreich weit verbreitet. Sie können durch die $\beta$-Glukuronidase hydrolytisch gespalten werden. Das Enzym ist spezifisch für $\beta$-Glukuronide, denn $\alpha$-Glukuronide oder auch $\alpha$ - und $\beta$-Glukoside werden nicht hydrolysiert (1). Der Reaktionsmechanismus verläuft wie folgt:<smiles>[R]O[C@H]1O[C@H](C(=O)O)[C@@H](O)[C@H](O)[C@H]1O</smiles>

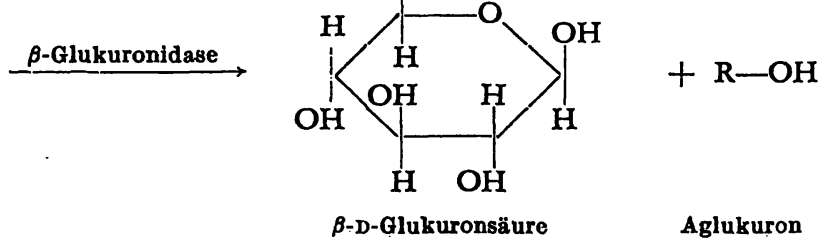

Die $\beta$-Glukuronidase besitzt zu den einzelnen Glukuroniden eine unterschiedliche Affinität (2). Für Glukuronide von Phenolphthalein, Östriol, Phenol, p=Chlorphenol undMenthol wurden die größten Hydrolysegeschwindigkeiten ermittelt. Deshalb sind auch diese Substrate zur Bestimmung des Enzyms am meisten angewandt worden. Bei Untersuchungen glukuronidasearmen Materials, beispielsweise menschlichen Serums, hat sich Phenolphthalein- $\beta$-D-glukuronid als Substrat bewährt. Bei der enzymatischen Spaltung bestehen bis zu einem bestimmten Maximum lineare Verhältnisse zwischen Hydrolyserate und Substratkonzentration; bei höheren Substratkonzentrationen tritt eine Hemmung auf, die nach genauen Analysen als reiner Subs̄trateffekt erkannt wurde $(3,4,5)$. Die Glukuronidhydrolyse verläuft meist linearproportional der Enzymkonzentration. Glukuronidasen verschiedener Herkunft haben ihr $\mathrm{pH}$-Optimum im sauren Gebiet, wobei die Werte in Abhängigkeit vom Ausgangsmaterial, von der Enzymdarstellungsmethode, vom Substrat, von der Substratkonzentration, von der Inkubationstemperatur und vom Reaktionspuffer zwischen $\mathrm{pH}$ 4,5-6,3 schwanken. Für Serum liegt das Optimum zwischen $\mathrm{pH}$ 4,5-5,0. Als Bebrütungstemperatur werden in den einzelnen Bestimmungsmethoden $37-50^{\circ}$ angegeben. Die Hydrolyserate ist auch vom Ionenmilieu abhängig. Allen Autoren hat sich $0,2 \mathrm{M}$ Acetatpuffer als günstigster Reaktionspuffer erwiesen (2).

Eine Reihe von Effektoren beeinflussen die $\beta$-Glukuronidaseaktivität. Aktivatoren sind Desoxyribonucleinsäure, Protamin, Rinderserumalbumin, Eieralbumin, Gelatine, Chymotrypsin, Spermin, Hefe-Ribonucleinsäure und Kaliumjodid. Glukuronsäureakzeptoren, wie Mono- und Polyhydroxyalkohole, aktivieren ebenfalls, woraus auf eine Transferasewirkung des Enzyms geschlossen werden kann $(6,7,8,9)$. Als Inhibitoren sind 1:2-Saccharolakton, Zuckersäure, D-Glukonsäure, DGlukuronsäure und andere $\beta$-Oxysäuren sowie monound dibasische Polyhydroxysäuren, Gallensäuren und Schwermetalle bekannt $(10,11,8)$. Auch spezifische Gewebs- und Seruminhibitoren wurden gefunden (12, 13).

Zur Aktivitätsmessung der $\beta$-Glukuronidase sind Bestimmungen der freigesetzten Glukuronsäure (reduktometrische Methode), des ungespaltenen Substrates (Naphthoresorcin-Methode) oder des fermentativ abgespaltenen Aglukurons möglich (2). Davon hat besonders die letztgenannte Möglichkeit Verbreitung gefunden. Bei der Wahl eines Substrates läßt man sich von folgenden Überlegungen leiten: 1. Das Substrat soll möglichst einfach darzustellen sein; 2 . das Enzym muß zum Substrat eine ausreichende Affinität besitzen; 3. das freigesetzte Aglukuron muß einfach, schnell und genau meßbar sein.

Angeregt durch die Untersuchungen von RoBrNson und Mitarbeitern (14) sowie BILLETT (15) arbeiteten wir eine Methode zur Bestimmung der Serum- $\beta$-Glukuronidase unter Verwendung von 8-Oxychinolin- $\beta$-D-glukuronid als Substrat aus. Dieses Glukuronid kann in sehr einfacher Weise kristallin dargestellt werden, und das Spaltprodukt 8-Oxychinolin läßt sich mit einer Farbreaktion nachweisen. 


\section{Methodik}

\section{Prinzip}

8-Oxychinolin- $\beta$-D-glukuronid wird durch die $\beta$-Glukuronidase des Serums in 8-Oxychinolin und $\beta$-D-Glukuronsäure gespalten. Nach Abstoppen der Enzymreaktion mit Kaliumsaccharat wird 8-Oxychinolin mit Tetra-o-dianisidin zu einem rot-violetten Azofarbstoff gekoppelt und die entstandene Farbe bei $546 \mathrm{~m} \mu$ im „Eppendorf“-Photometer gegen einen Leerwert ausgemessen. Der Leerwert enthält gleiche Bestandteile wie der Meßwert, nur fügt man Serum erst nach Zugabe des Inhibitors zu. Aus einer Eichkurve, aufgestellt mit Eichlösungen, die 2-40 $\mu \mathrm{g}$ 8-Oxychinolin $/ \mathrm{m} l$ enthalten, sind die den jeweiligen Extinktionen entsprechenden $\mu \mathrm{g}$ Mengen abzulesen.

\section{Substratdarstellung}

In Anlehnung an die Vorschriften von BraHM (16) sowie RoBINSON, SMrth und Williams (14) verabreichen wir 5 kräftigen Kaninchen je 5,0 g wäßrig gelöstes 8-Oxychinolinsulfat durch eine Schlundsonde. Der gesammelte 24-Stunden-Urin wird durch Glaswatte filtriert und auf $1 / 5$ seines Volumens eingeengt. Danach stellt man mit etwas Eisessig auf $\mathrm{pH} 4,0$ ein. In 48 Stunden fällt bei $0^{\circ}$ das Trihydrat von 8-Oxychinolin- $\beta$-D-glukuronid aus. Die dunkelgrünen Kristalle werden abgetrennt und $4 \mathrm{mal}$ aus heißem Wasser unter Zusatz von Tierkohle umkristallisiert. Die Ausbeute beträgt etwa 10,0 g. Die reine Substanz darf mit Tetra-o-dianisidin keine Färbung ergeben, da sonst noch Verunreinigungen enthalten sind (hauptsächlich freies Oxychinolin). Die analytischen Daten sind aus Tabelle 1 ersichtlich.

Tab. 1

Analytische Daten des dargestellten 8-Oxychinolin- $\beta$-D-glukuronids (Werte in \%)

\begin{tabular}{ccc}
\hline Atom & theoretischer Wert & gefundener Wert \\
\hline $\mathrm{C}$ & 48,00 & 47,92 \\
$\mathrm{H}$ & 5,60 & 5,65 \\
$\mathrm{O}$ & 42,67 & 42,68 \\
$\mathrm{~N}$ & 3,73 & 3,75 \\
\hline
\end{tabular}

Schmelzpunkt $154^{\circ}$; Löslichkeit in Wasser bis $8,0 \mathrm{mM}$ bei $20^{\circ}$

Bei der Substratdarstellung müssen die Tiere mit Trockenfutter ernährt werden. Unter Grünfutternahrung wird stark alkalischer Urin ausgeschieden (16); in alkalischem Milieu werden Glukuronide zerstört.

\section{Darstellung des Enzyminhibitors}

Der $\beta$-Glukuronidaseinhibitor Kaliumsaccharat wird nach E. FISCHER dargestellt (17).

\section{Eigenschaften des Azofarbstoffes}

Bildung und Stabilität des rot-violetten Farbkomplexes sind temperatur- und $\mathrm{pH}$-abhängig. Bei höherer Temperatur und alkalischem Milieu entwickelt sich die Farbe schneller, wird aber auch instabil. Ab pH 8,0 entsteht der Farbstoff schlagartig, blaßt aber schon nach einigen Minuten ab. Im Alkalischen gibt auch Serum eine Rotfärbung. Bei pH 4,0-6,0 bildet sich der Azofarbstoff langsamer und muß 30 Minuten bei $50^{\circ}$ entwickelt werden. Nach Abkühlen auf $0^{\circ}$ ist er auch in verschiedenen Konzentrationen über $100 \mathrm{Min}$. stabil. Vorversuche zeigten, daß bei $\mathrm{pH} \mathrm{4,5}$ und einer Temperatur von $50^{\circ}$ (das sind auch die Enzyminkubationsbedingungen) $1 \mathrm{mg}$ Tetra-o-dianisidin/Ansatz optimal ist. Das Absorptionsmaximum liegt bei $505 \mathrm{~m} \mu$. Aus technischen Grïnden haben wir jedoch bei $546 \mathrm{~m} \mu$ gearbeitet. Unter diesen Bedingungen geben Glukuronid, Glukuronsäure, Saccharat und Serum keine Rotfärbung. Zusatz bis $0,3 \mathrm{~m} l$ Serum verursacht keine Farbverluste durch Adsorption an das Serumeiweiß oder durch Hemmung der Farbentwíwicklung. Eine Enteiweißung ist unnötig, zumal die geringen Trübungen durch entsprechende Leerwerte eliminiert werden. Bei sehr geringen 8-Oxychinolinkonzentrationen (unter $5 \mu \mathrm{g} /$ Ansatz) läuft die Farbentwicklung etwas langsamer ab, so daß die Eichkurve in ihrem unteren Abschnitt leicht gekrümmt verläuft.

\section{Enzymkinetik}

Zur Bestimmung der optimalen Reaktionsbedingungen wurden der Einfluß von Temperatur, pH, Substrat- und Enzymkonzentration sowie Inkubationszeit auf die enzymatische Hydrolyse untersucht. Bekanntlich haben auch das Ionennilieu und die Ionenstärke des Reaktionspuffers einen Einfluß. Übereinstimmend wird für die $\beta$-Glukuronidase $0,2 \mathrm{M}$ Acetat-Puffer als optimal angegeben, so daß diesbezügliche Untersuchungen als unnötig erachtet wurden. Das Substrat wurde wegen seiner Schwerlöslichkeit in heißem Puffer aufgelöst. Im weiteren beziehen sich alle Angaben auf ein Ansatzvolumen von $1,0 \mathrm{~m} l$.

\section{Einfluß der Temperatur}

Bebrütet man drei Stunden 4,0 mM Substrat mit $0,1 \mathrm{~m} /$ Serum/ Ansatz bei pH 4,5 und verschiedenen Temperaturen, so ergibt sich eine ansteigende Spaltungsrate bis $60^{\circ}$. Bei höheren Temperaturen kommt es zu partieller Inaktivierung. Bei $80^{\circ}$ kann keine Aktivität mehr gemessen werden. Zur Ermittlung des Temperaturoptimums wurden die gewonnenen Ergebnisse nach der Arrbenius-Gleichung analysiert und in Abbildung 1 graphisch aufgetragen. Danach liegt das Temperaturoptimum bei $50^{\circ}$. Der Temperaturkoeffizient beträgt für die Hydrolyse $Q=2,0$. Die bemerkenswerte Hitzestabilität der $\beta$-Glukuronidase zeigt sich auch im getadlinigen Spaltungsverlauf über 10 Stunden (Abb. 5). Bewahrt man Serum vor der Inkubation 3 Stunden bei $50^{\circ}$ auf, resultiert kein Aktivitätsverlust.

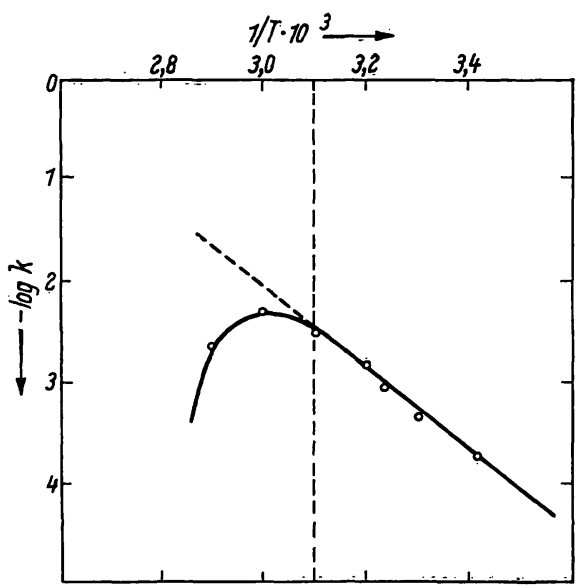

Abb. 1

Darstellung der Substratspaltung bei verschiedenen Temperaturen $\left(20-70^{\circ}\right)$ nach Arrbenius. Danach liegt das Temperaturoptimum der enzymatischen Reaktion bei 3,10 $\left(1 / \mathrm{T} \cdot 10^{3}\right)=50^{\circ}$

\section{Einfluß des $p H$-Wertes}

Unter unseren Versuchsbedingungen wurde als Optimum $\mathrm{pH}$ 4,5 ermittelt (Abb. 2). Dieser pH-Wert erwies sich auch bei verschiedenen Substratkonzentrationen als günstig. Hydrolysiert wurde bei den aufgezeichneten pH-Werten, die Anfärbung des freigesetzten 8-Oxychinolin erfolgte jedoch einheitlich bei pH 4,5, das mit $\mathrm{Zu}-$ gabe des Inhibitor-Farbreagenz eingestellt wurde. 


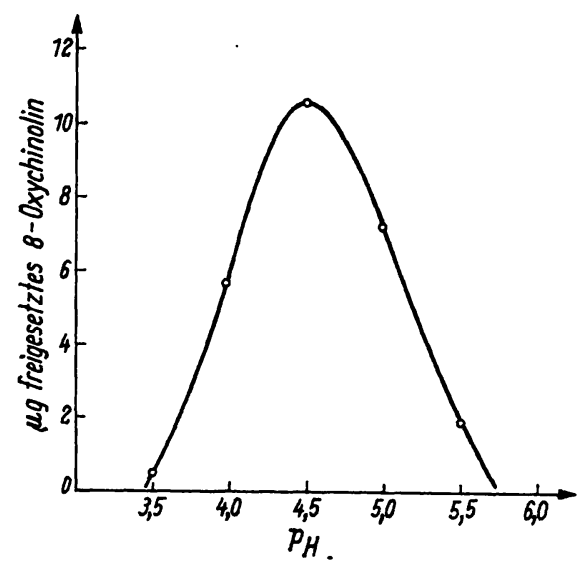

Abb. 2

Aktivität der $\beta$-Glukuronidase des Serums bei verschiedenem pH (Optimum $=\mathrm{pH} 4,5$ )

\section{Einfluß der Substratkonzentration}

Inkubiert man $0,1 \mathrm{~m} l$ Serum drei Stunden bei $\mathrm{pH} 4,5$ und $50^{\circ}$ mit verschiedenen Substratkonzentrationen $(1,0 \mathrm{~mm}$ bis $8,0 \mathrm{~mm} /$ Ansatz), erhält man eine für Enzymreaktionen charakteristische Substratkonzentration-Reaktionsgeschwindigkeitskurve (Abb. 3). Die Michaeliskonstante beträgt für Normalserum durchschnittlich $\mathrm{K}_{\mathrm{m}}=2,5 \cdot 10^{-3}\left(1 / \mathrm{K}_{\mathrm{m}}=400\right)$. Bis zu einer Substratkonzentration von $8,0 \mathrm{~mm}$ wird keine Substrathemmung beobachtet. Höhere Konzentrationen können wegen der Schwerlöslichkeit des Glukuronids nicht untersucht werden. Unter Berücksichtigung der Löslichkeitsverhältnisse wählten wir für weitere Untersuchungen eine Substratkonzentration von $4,0 \mathrm{~mm} /$ Ansatz.

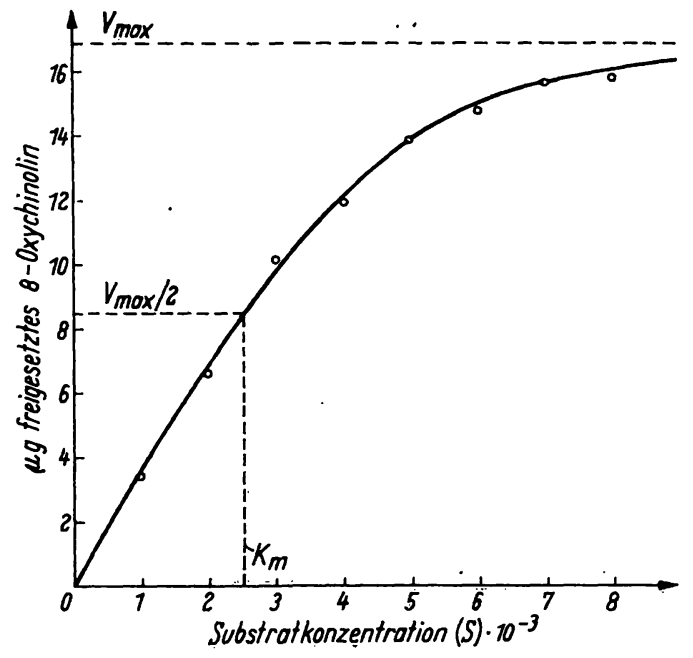

Abb. 3

Einfluß der Substratkonzentration auf die Enzymreaktion. $\mathrm{K}_{\mathrm{m}}=$ $2,5 \cdot 10^{-3} ; 1 / K_{m}=400$ (bezogen auf mittlere Werte von Normalserum)

\section{Einfluß ter Enzymkonzentration}

Bis zu einem Serumgehalt von 0,3 m//Ansatz besteht Proportionàlität zwischen Enzymkonzentration und Hydrolyserate unterer den gegebenen Versuchsbedingungen (Abb. 4). Bei größeten Serumkonzentrationen im Reaktionsansatz wird ein Teil des entwickelten Azofarbstoffes an Serumprotein adsorbiert, daraus resultieren zu niedrige Extiaktionen. Es muß aber auch unter Berücksichtigung der Befunde von Dohrmann und Uhues (12) ein spezifischer Hemmeffekt des Serums auf das Enzym diskutiert werden, der erst bei größeren Serummengen augenscheinlich wird. Aus diesen Gründen empfiehlt sich, zur Enzymaktivitätsbestimmụng $0,1 \mathrm{~m} l$ Serum zu benutzen. $\mathrm{Da}_{\mathrm{a}}$ beim Gerinnungsvorgang des Blutes $\beta$-Glukuronidase aus den Thrombozyten freigesetzt wird, muß vor Gewinnung des Serums der Gerinnungsprozeß abgelaufen sein (18).

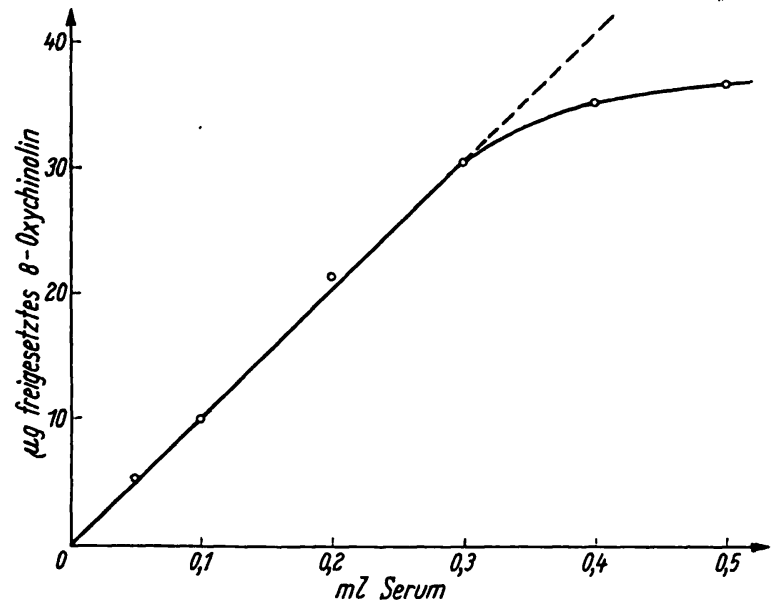

Abb. 4

Einfluß der Enzymkonzentration auf die enzymatische Hydrolyse. Bei größeren Serummengen als 0,3 m//Ansatz weicht die Kurve vom geradlinigen Verlauf $a b$

\section{Einfluß der Reaktionszeit}

Die enzymatische Hydrolyse von $4,0 \mathrm{~mm}$ 8-Oxychinolin- $\beta$-Dglukuronid durch $0,1 \mathrm{~m} /$ Serum bei $\mathrm{pH} 4,5$ und $50^{\circ}$ wurde über 10 Stunden verfolgt. In dieser Zeit verläuft die Hydrolyse als Reaktion nullter Ordnung (Abb. 5). Die konstante Hydrolyserate als Funktion der Bebrütungszeit beweist die Stabilität des Enzyms bei $\mathrm{pH} 4,5$ und $50^{\circ}$ über mindestens 10 Stunden und zeigt, daß dabei die Reaktion durch Hydrolyseprodukte (8-Oxychinolin und Glukuronsäure) nicht gehemmt wird.

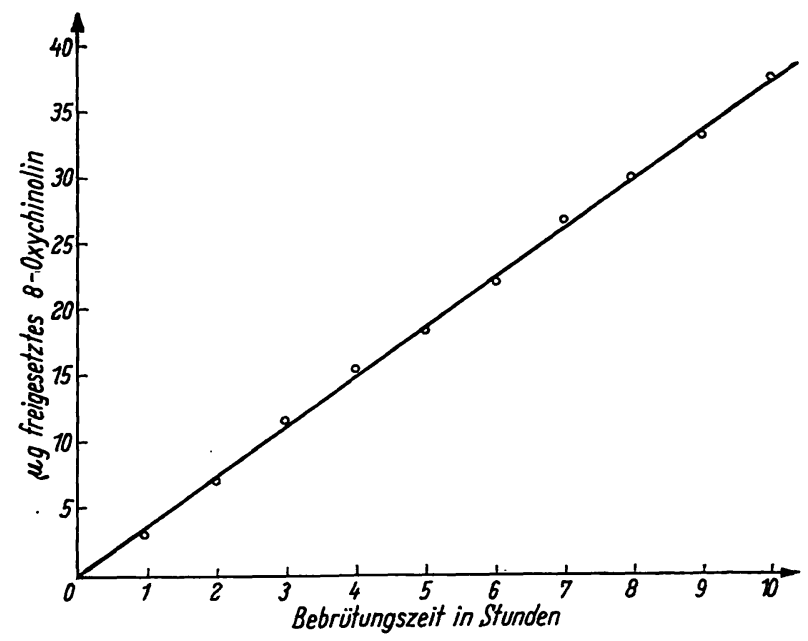

Abb. 5.

Spaltungsverlauf von 4,0 mM 8-Oxychinolin- $\beta$-D-glukuronid/ Ansatz durch $0,1 \mathrm{~m} l$ Serum bei $50^{\circ}$ und $\mathrm{pH} 4,5$ über verschiedene Bebrütungszeiten

\section{Haltbarkeit des Serumenzyms}

Bewahrt man Serum bei einer Temperatur zwischen $0-4^{\circ}$ auf, so kann auch nach 5-6 Tagen kein merklicher Aktivitätsverlust der $\beta$-Glukuronidase festgestellt werden.

Nach diesen Untersuchungsergebnịsen empfehlen wir für die Bestimmung der $\beta$-Glukuronidase im Serum ein Vorgehen wie in Tabelle 2 dargestellt. Von Normalserum werden unter diesen Versuchsbedingungen etwa 8-12 $\mu \mathrm{g}$ 8-Oxychinolin vom Glukuronid abgespalten (etwa 2\% Substratspaltung) und ergeben mittels der beschriebenen Farbreaktion Extinktionen von 0,2-0,3. 
Tab. 2.

Arbeits-Schema zur Bestimmung der $\beta$-Glukuronidase im Serum

Reaktionsmilieu: 0,2M Acetatpuffer $\mathrm{pH} 4,5$;

\section{Reagenzien}

Substrat: $4,4 \mathrm{~mm}$ 8-Oxychinolin- $\beta$-D-glukuronid $(165 \mathrm{mg} / 100 \mathrm{~m} / 0,2 \mathrm{M}$ Acetatpuffer $\mathrm{pH} 4,5)$

Inbibitor-Farbstoff-Reagenz: $22,5 \mathrm{mg} \mathrm{K-Saccharat}+10 \mathrm{mg}$ Tetra-o-dianisidin in ein Mikrobecherglas geben. Bei Gebrauch in $30 \mathrm{ml} 0,2 \mathrm{M}$ Acetatpuffer $\mathrm{pH} 4,5$ lösen. Ausreichend für je 5 Ansätze und Leerwerte.

Bestimmung

Bebrütungsansatz

Leerwert

$0,9 \mathrm{~m} / 4,4 \mathrm{~mm}$ Substratlösung

$+$

$0,1 \mathrm{~m} /$ Serum

(Substratkonzentration/Ansatz $=4,0 \mathrm{~mm}$ )

$0,9 \mathrm{~m} / 4,4 \mathrm{~mm}$ Subștratlösung

3 Stunden bei $50^{\circ}$ bebrüten

Danach je $3,0 \mathrm{~m} l$ Inhibitor-Farbstoff-Reagenz zugeben

(=2,25 mg K-Saccharat und 1,0 mg Tetra-o-dianisidin/Ansatz)

-

$0,1 \mathrm{~m} /$ Serum $^{1}$ )

Farbentwicklung $30 \mathrm{Min}$. bei $50^{\circ}$

Einstellen der Reaktionsgefäße in Eiswasser

Bei $546 \mathrm{~m} \mu$ in Küvetten von $1 \mathrm{~cm}$ Schichtdicke gegen den jeweiligen Leerwert photometrieren (z. B. „Eppendorf“Photometẹr)

\section{Berechnung}

$\mu \mathrm{g}$ freigesetztes 8-Oxychinolin aus der Eichkurve ablesen. Umrechnung in Internationale Einheiten ( $\mu$ Mol freigesetztes 8-Oxychinolin/Min./1000 m/ Serum) nach der Formel:

$$
\begin{aligned}
& \mathrm{x} \text { IE }=\frac{(8-\text { Oxychinolin in } \mu \mathrm{g}) \cdot 10000}{145,15 \cdot 180} \\
& \mathrm{x} \mathrm{IE}=(8-\text { Oxychinolin in } \mu \mathrm{g}) \cdot 0,383
\end{aligned}
$$

oder: in Einheiten, die definiert sind als $\mu \mathrm{Mol}$ freigesetztes 8-Oxychinolin $/ 60 \mathrm{Min} . / 1000 \mathrm{~m} / \mathrm{Serum}$ nach der Formel:

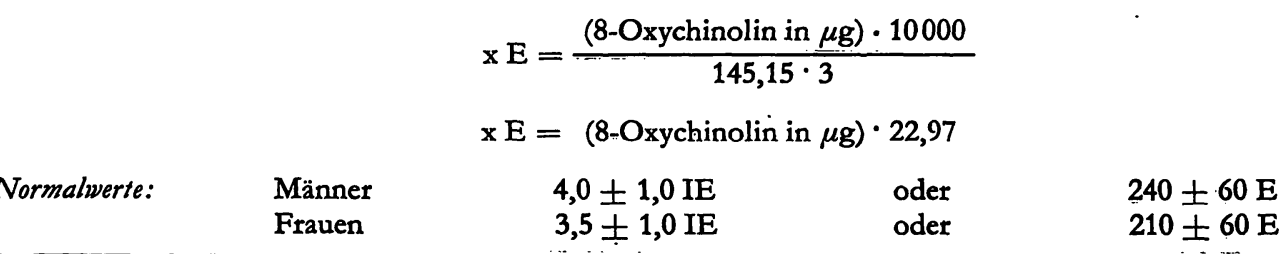

1) Wenn vor der Bebrütung Serum und Inhibitor gleichzeitig zugefügt werden, resultieren gleiche Leerwertextinktionen wie bei dem angegebenen Vorgehen. Die Vereinfachung ist also zulässig.

Dabei bleibt genügend Spielraum, um pathologische Aktivitätserhöhungen oder Erniedrigungen zu erfassen. Werden mehr als $40 \mu \mathrm{g}$ 8-Oxychinolin freigesetzt, muß die Farblösung vor dem Photometrieren entsprechend verdünnt werden.

\section{Ergebnisse}

\section{Normalwerte}

Die normalen Aktivitätswerte der $\beta$-Glukuronidase des menschlichen Serums wurden an 100 klinisch gesunden Blutspendern ermittelt. Dabei fanden sich als Mittelwerte für Frauen 3,5 $\pm 1,0 \mathrm{IE}$, für Männer 4,0 $\pm 1,0 \mathrm{IE}$. Die Umrechnung in Internationale Einheiten erfolgte nach der in Tabelle 2 angegebenen Formel. Eine Enzymeinheit isst definiert als $\mu \mathrm{Mol}$ freigesetztes 8-Oxychinolin/ Min. $/ 1000 \mathrm{ml}$ Serum. In Anbetracht der besonderen kinetischen Verhältnisse der $\beta$-Glukuronidase (langsame
Spaltung) und hinsichtlich klinischer Belange wird empfohlen, die Enzymeinheit als $\mu \mathrm{Mol}$ freigesetztes 8Oxychinolin/60 Min./1000 ml Serum (bezogen auf die beschriebenen Versuchsbedingungen) anzugeben. Als Normalwerte gelten dann für Frauen $210 \pm 60 \mathrm{E}$, für Männer $240 \pm 60$ E. Die höchste im Normalserum gemessene Aktivität betrug $310 \mathrm{E}$. Eine derartige Berechnung ist trotz Anwendung einer „ZweipunktMethode" zulässig, da gezeigt wurde, daß eine Reaktion nullter Ordnung vorliegt.

In unserem Material - Personen im Alter von 18 bis 75 Jahren - lagen übereinstimmend mit der Literatur die Aktivitätswerte bei Männern etwas höher als bei Frauen. Eine Altersabhängigkeit zeichnete sich nicht ab. Bei Frauen in der Menopause konnten wir im Gegensatz zu anderen Untersuchern keine deutlich höheren Werte finden $(19,20,21,22,23)$. 


\section{Diskussion}

Von den drei Möglichkeiten zur Aktivitätsmessung der $\beta$-Glukuronidase haben lediglich Methoden mit Nachweis des Aglukurons weitere Anwendung gefunden. Meist wurden die Glukuronide von Menthol, Phenol und Phenolphthalein als Substrate benutzt. Schwierigkeiten machte die Aktivitätsmessung in fermentarmen Lösungen, wie beispielsweise in menschlichem Serum. Hierfür konnte erfolgreich Phenolphthalein- $\beta$-D-glukuronid benutzt werden, das eine hohe Affinität zum Enzym besitzt $(24,25,26,23)$. Ähnlich günstig wäre Östriolglukuronid, das aber schwer zugänglich ist. Aber auch die „Phenolphthaleingluküronidmethode" hat einige Fehlerquellen. Bei dieser Methode wird nach erfolgter Inkubation der Reaktionsansatz alkalisiert und die durch das abgespaltene Phenolphthalein hervorgerufene Rotfärbung bei $552 \mathrm{~m} \mu$ ausgemessen. Das Substrat ist nicht kristallin zu erhalten und kann nur biosynthetisch als Cinchonidinsalz nach schwieriger und langandauernder Prozedur dargestellt werden. Das Salz muß dann in die eigentliche Substratlösung überführt werden. Dementsprechend sind die kommerziell hergestellten Präparate sehr teuer. Nach Fishman (25) ist zur $\beta$-Glukuronidasebestimmung im Serum eine Bebrütungszeit von mindestens 15 Stunden notwendig. Die entwickelte Rotfärbung ist nur für die Dauer von 10 Minuten stabil, und bei dem großen molaren Extinktionskoeffizienten des Phenolphthaleins in alkalischem Milieu ergeben sich schon bei geringsten $\mathrm{pH}-\mathrm{Schwankungen} \mathrm{Meßfehler.} \mathrm{Nachteilig}$ wirkt sich auch die bekannte Substrathemmung auf die $\beta$-Glukuronidase bei verhältnismäßig kleinen Phenolphthaleinglukuronidkonzentrationen aus. Für einige Enzympräparate liegt die Grenze der zulässigen Substratkonzentration unter dem $\mathrm{K}_{\mathrm{m}}$-Wert (4). Fehler sind auch durch Mitreißen von kleinen Phenolphthaleinmengen durch das manchmal notwendige Ausfällen von Protein aus enzymhaltigen Lösungen möglich $(27,28)$. Diese geschilderten Nachteile sind nach der Modifikation von Dohrmann $(24,20)$ weitgehend zu umgehen, jedoch erscheint uns die empfohlene kinetische Auswertung für größere Reihenuntersuchungen in der Klinik zu umständlich. Histochemisch kann Phenolphthalein- $\beta$-Dglukuronid nicht benutzt werden. Methoden, die Bromnaphthol- (21) oder Umbelliferonglukuronid (22) als Substrat benutzen, sind unzweckmäßig, da Bebrütungszeit bzw. Ansatzmengen sehr groß gewählt werden müssen. Bẹi Anwendung von Ümbelliferonglukuronid kann ikterisches Serum nicht untersucht werden, da dieses beim fluorometrischen Nachweis des freigesetzten Umbelliferon fluoreszenzlöschend wirkt. Phenylglukuronid (29) und p-Chlorphenylglukuronid (5) werden zu langsam gespalten, um sie zur Bestimmung der Serumglukuronidase zu benutzen.

Als Kriterien für die Brauchbarkeit und Vorteilhaftigkeit einer Enzymbestimmungsmethode unter Benutzung von 8-Oxychinolin- $\beta$-D-glukuronid als Substrat müssen folgende Punkte angeführt werden:
1. Das Substrat läßt sich leicht in kristalliner Form darstellen.

2. Das Enzym besitzt zum 8-Oxychinolin- $\beta$-D-glukuronid eine große Affinität, so daß verhältnismäßig kurze Bebrütungszeiten gewählt werden können.

3. Das freigesetzte 8-Oxychinolin läßt sich durch eine empfindliche Farbreaktion mit Tetra-o-dianisidin nachweisen.

4. Der entstehende Farbstoff ist bei $0^{\circ}$ über $100 \mathrm{Min}$. stabil.

5. Das ungespaltene Glukuronid, Glukuronsäure, Serum und Kaliumsaccharat geben bei den Versuchsbedingungen keine Färbung.

6. Der Fehler der Methode beträgt etwa $\pm 1 \%$.

Bei Untersuchungen der Enzymkinetik mit menschlichem Serum erwies sich 0,2 $\mathrm{M}$ Acetat-Puffer $\mathrm{pH}$ 4,5 als bestes Ionenmilieu. Die Bebrütungszeit von 3 Stunden könnte bei Anwendung höherer Substratkonzentrationen als 4,0 mM/Ansatz noch verkürzt werden, jedoch müssen Konzentrationen von $8,0 \mathrm{~mm}$ wegen der Schwerlöslichkeit der Substanz als obere Grenze gelten. Ein Substrathemmeffekt konnte bei den untersuchten Substratkonzentrationen nicht beobachtet werden. Das Ergebnis der Arrbenius-Analyse und der geradlinige Spaltungsverlauf über 10 Stunden zeigen, daß bei der verhältnismäßig hohen Bebrütungstemperatur von $50^{\circ}$ keine wesentliche Denaturation des Enzymproteins während der dreistündigen Bebrütung auftritt. Die große Temperaturstabilität läßt sich außer für Serum- $\beta$ Glukuronidase auch für gereinigte Enzympräparate zeigen $(30,31)$. Während der Bebrütung fällt normalerweise kein Eiweiß aus. Wir konnten eine Proteinpräzipitation bisher lediglich bei Serum eines Patienten mit Morbus Waldenström beobachten. Allerdings kann die Enzymkonzentration nicht wesentlich gesteigert werden, da größere Serummengen im Ansatz die Farbreaktion stören und spezifische Hemmeffekte auftreten. Die Methode läßt sich wahrscheinlich bei Untersuchungen eiweißreicher Enzymlösungen in dieser Form nicht benutzen. Für Bestimmungen der $\beta$-Glukuronidase im Serum bietet sie sich jedoch wegen ihrer Einfachheit und Billigkeit an, zumal alle notwendigen Reagenzien auch in einem kleineren Laboratorium selbst herstellbar sind und geringe apparative Anforderungen gestellt werden. Nicht unerwähnt soll bleiben, daß 8-Oxychinolin- $\beta$-Dglukuronid auch zur histochemischen Darstellung der $\beta$-Glukuronidase benutzt werden kann. Bei der wachsenden klinischen Bedeutung des Enzyms erschien uns die Ausarbeitung einer neuen und einfachen Bestimmungsmethode gerechtfertigt.

Ich möchte nicht versäumen, an dieser Stelle den Herren von der Firma „Arzneimittel“ Naumburg für die UUberlassung von 8-Oxychinolinsulfat und Frau Dr. L. REDINGER - Deutsche Akademie der Wissenschaften zu Berlin, Institut für Organische Chemie - für die Analyse des biochemisch dargestellten 8-Oxychinolin- $\beta$-Dglukuronid recht herzlich zu danken. Fräulein G. Murz danke ich für wertvolle technische Mitarbeit. 


\title{
Literatur
}

1. Helfrich, B. und G. Sparmberg, Hoppe-Seyler's Z. physiol. Chem. 221, 92 (1933). - 2. Fishman, W. H., in: Sumner J. B. und K. Mrrbäck, The Enzyms, Bd. I/1. Academic Press Inc. Publ., New York (1950). - 3. Fishman, W. H., J. biol. Chemistry 131, 225 (1939). - 4. Nnmo-Smith, R. H., Biochim. biophysica Acta (Amsterdam) 50, 166 (1961). - 5. SPENCER, B. und R. T. WilliIAMS, Biochem. J. 48, 537 (1951). - 6. Abur-Fadr, M. A. M. J. Clin. Path., London 10,387 (1957). - 7. Bernfeld, P. und W. H. Fishiman, Science (New York) 112, 653 (1950).-8. NAYYAR, S.N. und D. GuICK, J. biol. Chemistry 222, 73 (1956). - 9. SMrrH, E. E. B. und G. T. MrLls, Biochem. J. 52, 464 (1952). - 10. Levvy, G. A., A. J. Hay und C.A.MarSH, Biochem. J. 65, 203 (1957). - 11. LEvvy, G.A. und C. A. MARSH, Nature (London) 180, 197 (1957). - 12. DohrMANN, R. und H. J. UhLes, Klin. Wschr. 41, 527 (1963). - 13. WALKER, P. G. und G. A. LeVVY, Biochem. J. 54, 56 (1953). 14. Robinson, D., J. N. Smith und R. T. Williams, Biochem. J. 53, 125 (1953). - 15. Billett, F., Biochem. J. 57, 159 (1954). - 16. Brahm, C., Hoppe-Seyler's Z. physiol. Chem. 28, 439 (1899). 17. Fischer, E., Anleitung zur Darstellung organischer Präparate,
9. Aufl., Verlag Friedrich Vieweg und Sohn, Braunschweig (1920). - 18. Dohrmann, R. und R. KLespre, Klin. Wschr. 38, 595 (1960). - 19. Dohrmann, R., Zschr. exper. Med. 132, 585 (1960). - 20. Dohrmann, R., Habil.-Schrift, Bonn (1961). 21. Goldbarg, J. A., E. P. Pineda, B. M. Banks und A. M. Rutendurg, Gastroenterology, Baltimore 36, 192 (1959). - 22. Hackensellner, H. A., F. Seelich und H. Lind, Wien. klin. Wschr. 70, 28 (1958). - 23. Talalay, P., W. H. Fishman und C. Huggn, J. biol. Chemistry 166, 757 (1946). - 24. DohrmanN, R., Dtsch. Arch. klin. Med. 206, 322 (1960). - 25. Fishman, W. H., B. SPRINGRR und R. BRUNitit, J. biol. Chemistry 173, 449 (1948). - 26. Di Somma, A. A., J. biol. Chemistry 133, 277 (1940). — 27. Goldstein, G., Clin. Chem. (New York) 7, 136 (1961). - 28. Plaice, C. H. J., J. Clin. Path., London 14, 661 (1961). - 29. KerR, L. M. H., A. F. GraHAM und G. A. Levvy, Biochem. J. 42, 191 (1948). - 30. Methressel, J. und R. Nirrus, Acta biol. med. german. 13, 411 (1964). - 31. Nirrus, R., Inaug.-Diss., Halle (1961).
Dr. med. R. Nilius

I. Med. Klinik der Universität Halle-Wittenberg

X 402 Halle/Saale, Leninallee 22

\section{Die Bestimmung der Triglyceride im Serum mit der Hantzsch-Reaktion}

\author{
Von F. Dunsbach \\ Aus dem Chemisch-Physiologischen Institut des Allgemeinen Krankenhauses St. Georg, Hamburg \\ (Leiter: Dr.pbil. F. Fretwurst)
}

(Eingegangen am 26. November 1965)

\begin{abstract}
Es wird eine Methode zur Bestimmung der Triglyceride im Blutserum mit Hilfe der Hantzscb-Reaktion beschrieben. Nach adsorptiver Abtrennung der übrigen glycerinhaltigen Lipidfraktionen wird das durch Verseifung der Triglyceride erhaltene Glycerin mit Perjodat zu Formaldehyd oxydiert und der entstandene Formaldehyd mit Acetylaceton und Ammoniumsalz in essigsaurer Lösung zu Diacetyldihydrolutidin umgesetzt. Die gelbgefärbte amylalkoholische Lösung wird bei $400-420 \mathrm{~m} \mu$ photometriert.

A method is described for the determination of triglycerides in blood serum with the aid of the Hantzsch reaction. After removal of the remaining glycerol-containing lipid fractions by adsorption, the glycerol obtained by saponification of the triglycerides is oxidised to formaldehyde with periodate and the resulting formaldehyde converted into diacetyldihydrolutidine with acetyl acetone and ammonium salt in acetic acid solution. The yellow amyl alcoholic solution is quantised photometrically at $400-420 \mathrm{~m} \mu$.
\end{abstract}

Die steigende Bedeutung der Erfassung von Lipoidstoffwechselstörungen durch biochemische Methoden führte in den letzten Jahren zu einer Reihe von Veröffentlichungen über die Bestimmung der Triglyceride im Blutserum und Blutplasma. Dabei sind bis heute drei in ihren Grundzügen verschiedene Methoden bekannt geworden. So bestimmten vAN HANDEL und ZILVERSMIT (1) die Triglyceride nach Abtrennung der übrigen glycerinhaltigen Serumlipide (Adsorption an „Doucil") durch Verseifung mit alkoholischer Kalilauge, Oxydation des entstandenen Glycerins mit Perjodat zu. Formaldehyd und Umsetzung des Formaldehyds mit Chromotropsäure nach LAmberT und NeIsh (2). Mendelson und Antonis (3) bedienten sich zur Bestimmung des freigesetzten Glycerins der Skraup'schen Chinolinsynthese, bei der Glycerin mit o-Aminophenol in Schwefelsäure bei Anwesenheit eines Oxydations- mittels zu 8-Oxychinolin umgesetzt wird, dessen Magnesiumsalz fluorimetrisch gemessen wird. EGGSTEIN und KREUTTZ (4) beschrieben eine direkte enzymatische Methode zur Bestimmung der Triglyceride, die auf der Bildung von $\alpha$-Glycerophosphat aus dem durch Verseifung freigesetżten Glycerin und ATP bei Anwesenheit von Glycerokinase beruht.

Die hier beschriebene Methode lehnt sich insofern an die von VAN HANDEL und ZILVERSMit an, als auch hier die Trennung der Triglyceride von den übrigen glycerinhaltigen Bestandteilen mit Hilfe eines Adsorbens, Verseifen der Triglyceride zu Glycerin und Fettsäuren und Oxydation des Glycerins mit Perjodat zu Formaldehyd erfolgt. Zur Bestimmung des Formaldehyds dient die Reaktion nach HANIZSCH (5). Diese Reaktion wurde von Nasf (6) zur Bestimmung des Formaldehyds beschrieben und beruht darauf, daß Formaldehyd mit Acetyl- 